\title{
El pensamiento complejo como propedéutico para la transgestión de los saberes matemáticos
}

Milagros Elena Rodríguez ${ }^{1}$

\section{INFORMACIÓN DEL ARTÍCULO}

Recibido: 30.04 .2020

Aprobado: 30.05 .2020

\section{Palabras claves:}

Transparadigmática,

Complejidad,

Propedéutico,

Descolonización,

Proceso inclusivo.

\section{RESUMEN}

La transgestión de los saberes matemáticos atiende a una subversión transparadigmática, en un proceso inclusivo donde los saberes matemáticos circunscriben los conocimientos científicos de la matemática; pero también los saberes matemáticos soterrados; los de los grupos étnicos, la Etnomatemática, de la cotidianidad; esto es el patrimonio cultural matemático. Esta investigación tiene como objetivo analizar el pensamiento complejo como propedéutico de la transgestión de los saberes matemáticos usando el enfoque hermenéutico comprensivo en los tres momentos planteados en Santos (2003), en los tiempos: el analítico, el empírico y el propositivo. Concluyéndose, que en los saberes matemáticos la información transmitida no capta todo el significado de la matemática en la cotidianidad y cultura de los grupos étnicos; debe romperse el cerco en las construcciones matemáticas de la objetividad determinada del científico y explorar los saberes matemáticos en los grupos étnicos es una tentativa virgen para comenzar en las indagaciones de riqueza inconmensurable por crear en la descolonización de ellos, esto es urgente e implica ampliar la comprensión de dichos saberes. Los saberes patrimoniales entrañan en sí mismo la complejidad, y pueden ser transgestionados y salvaguardados, su transgestión consciente a un docente que atiende a una formación transcompleja de la matemática formado no sólo para el saber eficaz sino en la inteligencia integral: analítica, sistémica, sensible, corporal y profundamente humana.

\section{The complex thinking as propedéutico for the transgersion of mathematical knowledge}

\begin{abstract}
The transgestion of mathematical knowledge attends to a transparadigmatic subversion, in an inclusive process where mathematical knowledge circumscribes the scientific knowledge of mathematics; but also the buried mathematical knowledge; those of ethnic groups, Ethnomathematics of everyday life; this is the mathematical cultural heritage. The objective of this research is to analyze complex thinking as a propaedeutic of the transgestion of mathematical knowledge using the comprehensive hermeneutic approach in the three moments proposed by Santos (2003),

\footnotetext{
1 Post Doctora en Ciencias de la Educación. Profesora Investigadora de la Universidad de Oriente. Email melenamate@hotmail. com (1): https://orcid.org/0000-0002-0311-1705
} 
in the times: the analytical, the empirical and the propositive. Concluding, that in the mathematical knowledge the information transmitted does not capture the full meaning of mathematics in the daily life and culture of the ethnic groups; the bars must be broken in the mathematical constructions of the determinate objectivity of the scientist and exploring the mathematical knowledge in the ethnic groups is a virgin attempt to begin in the investigations of immeasurable wealth to be created in the decolonization of them, this is urgent and involves expanding the understanding of those knowledges. The heritage knowledge itself involves complexity, and can be trans-managed and safeguarded, its conscious transgestion to a teacher who attends a transcomplexity formation of mathematics formed not only for effective knowledge but in the integral intelligence: analytical, systemic, sensitive, bodily and deeply human.

\section{Introducción}

En la presente investigación se usa el enfoque hermenéutico comprensivo, en los tres momentos planteados en Santos (2003): el analítico, el empírico y el propositivo, analizando el pensamiento complejo como propedéutico de la transgestión de los saberes matemáticos. Sin duda, la autora desea escapar del encierro paradigmático para visionar críticamente la transgestión; el prefijo trans en este caso insinúa ir más allá de una gestión; es el "empeño en dejar los pisos o encierros en el análisis es claro: los paradigmas encierran, determinan y reducen el objeto de estudio en cualquier campo, subyugando al sujeto que se cree conocedor; son consecuencias, del proyecto hegemónico de la modernidad" (Rodríguez, 2017c, p.119).

\section{Fundamentación teórica}

La palabra rizoma que se usa de manera envolvente en los subtítulos de la presente investigación tiene una insinuación circundante, atiende a Deleuze \& Guattari (1980) en el que de manera compleja puede ser conectada con cualquier otro los razonamientos y ramas que constituyen la disposición; es una anti-genealogía que rompe con las estructuras estáticas divisorias de presentar las investigaciones en las que las partes se dividen indisolublemente en un ir, si un venir. Acá la organización no responde a ningún modelo estructural o generativo. Más adelante, la complejidad explicitada dará más claramente la explicación de tal denominación rizomatica.

Es menester, precisar lo que significa saberes matemáticos; estos incluyen los conocimientos científicos de la matemática; pero también los saberes matemáticos soterrados, no tomados en cuenta en el filo de la ciencias en palabras de Foucault (1986); entre ellos los de los grupos étnicos, la etnomatemática, de la cotidianidad, el patrimonio cultural matemático; aquellos saberes que la tríada matemática-cotidianidad-y pedagogía integral salvaguarda; convoca al rescate de la matemática en el aula de clase a través del uso de los tres canales de aprendizaje, al diálogo como "herramienta que lleva a establecer la relación sujeto-sujeto, entre el docente y el estudiante, donde éste 
último se apropia de su aprendizaje, rescatando para ello el amor y pasión por la ciencia matemática, usando elementos de su cotidianidad y cultura" (Rodríguez, 2010b, p.3).

Para que esto sea posible en la visión de dicha tríada, y que se considere al igual grado de importancia los saberes matemáticos científicos y los saberes matemáticos soterrados hace falta sin duda un pensamiento complejo que abra puentes de conexiones entre ellos y los reconvocada en igual grado de importancia; no "busca unificar todo lo separado en un pensamiento de completud, sino lanzar un desafío en pos de la religación y de la complejidad (...) el pensamiento complejo implica la integración de la sobredicho en un principio relacional y rotativo continuo" (Morín, 1992, p.10).

De ello se trata, al asumir el pensamiento complejo como propedéutico de la transgestión de los saberes matemáticos; no se trata de abandonar la disciplina matemática su esencia abstracta y sus procesos dialógicos del pensamiento; por el contrario es integrarlo transdiciplinarmente; sin resquemos de perdida de cientificidad con los conocimientos no tomados en cuenta por la ciencia y la modernidad impuesta. No debe haber resquemor; pues por ejemplo en la enseñanza de la matemática renovada y consustanciada con la vida del discente, que forma parte de la transgestión en construcción, puede tomarse en cuenta la transposición didáctica que no viola los preceptos de la ciencia matemática; pues a ello atiende el concepto de vigilancia epistemológica.

El principio de vigilancia epistemológica, según Gutiérrez (2016) es lo que el enseñante debe cuidar permanentemente, o sea qué relación tiene el objeto de enseñanza con el objeto matemático académico, cuál es la adecuación realizada. La distancia que separa el saber sabio del saber enseñado, es la herramienta que le permite al docente ejercer su vigilancia epistemológica. Es decir, dudar sistemáticamente si el objeto enseñado es el objeto a enseñar que se proponía, es decir, que el objeto transformado no pierda la esencia del saber sabio. Para el docente, la transposición didáctica es una herramienta primaria, por el paso del saber "sabio al saber enseñado que le permite recapacitar, tomar distancia, interrogar las evidencias, poner en cuestionamiento las ideas simples, desprenderse de la familiaridad engorrosa de su objeto de estudio. En una palabra, lo que le permite ejercer su vigilancia epistemológica (Chevallard, 1991, p.16).

En todas estas situaciones interviene el pensamiento complejo que es según "en esencia, el pensamiento que integra la incertidumbre y que es capaz de concebir la organización, que es capaz de religar, de contextualizar, de globalizar, pero al mismo tiempo, de reconocer lo singular y lo concreto" (González, 1997, p.22). Se trata con ello en la hermenéutica que se hace acá fuera de la rigidez de lo encerrado de la matemática como parcela, para abrirla como conocimiento derecho y alimento del desarrollo de un país. Así, y sin animadversión la transgestión debe repensar incluso en la creación de las teorías matemáticas y el bienestar o normativa ética a la que va dirigida. Entonces no es sólo la crítica de cómo se lleva su enseñanza; intervienen también las creencias e imágenes ante el mundo de la ciencia legado de la humanidad: la creación matemática. 
Desarrollar un pensamiento complejo en los saberes matemáticos implica: aprender a pensar, a reflexionar de una manera abierta, libre, indagando, descubriendo con actitud crítica, ética, estética y gnoseológica frente al mundo, al saber matemático, a la sociedad y a sí mismo. El pensamiento complejo es circular, porque facilita el establecimiento de conexiones de causalidad no lineales y la identificación de propiedades emergentes, además de dar más poder y flexibilidad en la resolución de problemas. La circularidad del pensamiento permite lograr mayor rendimiento con menor esfuerzo, rendimiento que se logra por el apoyo que da el todo a las partes y las partes al todo, para entrar en la complejidad relacionando lo que está separado sin quedarse en lo simple, considerando el enmarañamiento de datos sin reducirse a una explicación única, pero sin caer en las contradicciones perezosas. Atiende la teoría de la complejidad a la matemática fráctalica o compleja, como una de sus bases.

El pensamiento complejo desarrollado entonces, en las mentes y ya luego asimilado en el accionar de los seres humanos y viceversa debe llevar a una cercanía a una nueva forma de mirada de la vida, un transparadigma que no se permite el reduccionismo, Morín (1998) propugna la complejidad como una postura que se promueve día a día como categoría que es tomada como válida en la creación del conocimiento matemático.

La complejidad trasciende lo evidente lo reducido e incurre en todo lo acabado y definitivo de matemática, su educación; pero también lo que la tradicionalidad y reduccionismo ha abandonado de la matemática. Se vincula ciegamente el pensamiento complejo a un sistema de saberes para comprender al mundo desde la matemática siendo capaz de ir más allá de los límites que a sí mismo se impone los conocimientos cientificistas de la matemática. "Es el pensamiento que pone orden en el universo y persigue el desorden, el orden se reduce a una ley o a un principio, la simplicidad observa lo único o lo múltiple pero no ambos juntos" (Morín, 2004, p.23).

Por otro lado, hablando de los conocimientos matemáticos soterrados, colonizados, sin duda en cada país y sus grupos étnicos se han desarrollado desde sus inicios manifestaciones culturales que están cargadas de contenidos matemáticos. En Venezuela en particular, muchas de ellas han sido desvalorizadas destruidas u olvidadas desde el momento de la invasión europea a nuestro continente, con la destrucción de muchos de nuestros patrimonios "el desarrollo matemático de los pueblos indígenas fue influenciado y en algunos casos destruido por el proceso de colonización" (Díaz, 2002, p.5).

Desde luego en los saberes matemáticos muchos de ellos se han perdidos y otros han sido soterrados en tal proceso colonizado. Y con ello se ha impuesto en el aula de clase una enseñanza de saberes matemáticos científicos modernistas olvidando con ello los saberes de los grupos sociales; el pensamiento complejo como abrazador no incluyente pretende entonces dar un viraje a la gestión tradicional de la matemática. 


\section{Propuesta innovadora}

El momento analítico y empírico del enfoque hermenéutico se presenta en el siguiente rizoma 1.

\subsection{Rizoma 1: Un modo de visionar el estado del arte de la problemática}

La institución educativa moderna fue creada para servir al Estado nación, es una creación de la modernidad al igual que la educación. De este modo, la idea de formación del ciudadano está asociada a la forma histórica de una organización social, para preparar ciudadanos leales, obedientes, sumisos, con las destrezas necesarias definidas por los dueños de las fábricas. Rodríguez (2012) afirma que se le concede gran importancia a las cantidades, a la distancia y a la ubicación, pero muy poco o nada a lo subjetivo, a los valores, a las relaciones, a la humanización, la cultura nuestra y al contexto.

En base a esta problemática, y no se refiere solo al pasado, pues aún los rezagos están ahí; aquí al lado, adentro, se generan en las funciones de las instituciones educativas la crisis de paradigma e incita a una ruptura que propicia otra forma de pensar y actuar al repensar de la con-formación del ciudadano desde la Educación Matemática; sobre todo con la crisis de la matemática en el aula y con el surgimiento de la sociedad de la información que desde luego obliga a redefinir el papel del docente de matemáticas en las aulas; cuestiones que corrobora Rodríguez (2010a) y Rodríguez (2011). Y desde luego ello toca como gestiona la matemática ante la vida de las personas; como la utiliza como ejercicio de poder el docente y como ella se muestra inalcanzable en la vida del discente.

Se consciente que el lugar privilegiado de construcción de los saberes matemáticos y transgestión del mismo, es el proceso de educación dialógica, problematizadora, de la que Freire $(1973,2009)$ estudia, en ella, a través del diálogo creador, se crea y se re-crea el conocimiento humano que niega el método unidireccional formulado por la educación bancaria, en palabras tantas veces pronunciadas por Paulo Freire, ya que da coexistencia a una comunicación de ida y vuelta, y elimina la contradicción entre educadores y discentes.

Esta situación oscura que se parece al pesimismo es necesario asumirla como sinceridad, sin cortapisas, sin miedo al devenir de ello, al fin de dar un viraje a la transgestión educativa tradicionalista en Venezuela. Entre los problemas que enfrenta la gestión de la matemática en general se encuentran: el saber convivir con diferentes visiones de ver el conocimiento de las otras ciencias en la matemática (es decir, la negación de la propia esencia de su transdisciplinariedad), de asumirlo, de vivirlo; de construirlo, de valorarlo y aceptarlo en muchos casos. 
La ceguera del ciudadano modernista profundamente esclavo del sistema y de su propio egoísmo esta ceguera ética en palabras de Morín (2006) es la consecuencia fatal de un individuo ciego en su formación, que sus acciones lo llevan a destruirse a sí mismo. Es así como, la formación del ciudadano como el capital intelectual más importante a gestionar debe ser el objetivo de la educación actual; pero no cualquier formación; sino aquella que tome en cuenta "la regeneración moral que necesita la integración, en nuestra propia conciencia y personalidad, de los preceptos de la autoética, a fin de reactivar nuestras potencialidades altruistas y comunitarias" (Morín, 2006, p. 194). Es volverse hacia la formación continua, más allá de la humanización, de la ecología, de la ética tradicionalista que solo el ser humano puede construir. Aquí la matemática debe intervenir con su aporte al ciudadano y al desarrollo de un país.

Es pensar en una manera de prepararse para habitar el planeta, lo que se denomina ecosofía, aquella visión amplia y fuera de todo paradigma que el noruego Arne Naess en 1960 creo y que más tarde Feliz Guattari con sus tres ecologías ha complejizado con las ideas de filosofo de las luces complejas Edgar Morín, de las que tantas veces su discípulo Rigoberto Pupo ha escrito y James Lovelock hace eco en sus obras magistrales.

La ecosofía "propone trabajar a escala planetaria; propagar orientaciones disidentes que creen rupturas significativas en la vida actual; (...) integrar antropocentrismo y naturaleza; practicar acciones que incluyan ecología social, mental y medio ambiental; luchar contra el hambre; frenar la deforestación" (Pupo, 2013, p.3). En ese proceso se produce la cultura como esencialidad humana son ideas que comparte la autora con Pupo (2013) quién afirma que la visión ecosófica prepara ante todo para conocer al hombre, transdisciplinariamente, como sujeto complejo, en relación con el inserto en la cultura, y con ello, prepararlo para el trabajo creador y la vida con sentido.

La formación ética, como un valor inaplazable en estos tiempos, es un elemento significativo de primera en la sociedad del conocimiento. En primer lugar, porque contribuye a mejorar y actualizar permanentemente los conocimientos de las personas, con la ética como guía de sus acciones. En segundo lugar, y no menos importante, la impulsadora de otros valores del individuo, muchas veces perdidos en detrimento de otros intereses particulares. "La ética se construye desde una práctica del docente, desde la realidad vital, desde la vida cotidiana, de la necesidad de saber cómo actuar en cada situación concreta. (...). Esto requiere reflexión, sensibilidad, argumentación, desarrollo de hábitos" (Rodríguez, 2011, p.177). Como ejercicio ético profundo la salvaguardar del patrimonio cultural de los saberes matemáticos con la Etnomatemática. Es ir a los grupos étnicos a sus procesos dialógicos y constructivos de sus artefactos con alto contenido matemático y con ella promover la historia del país de la matemática en nuestro país. Esta debe ser una tarea de la transgestión de los saberes matemáticos.

La Etnomatemática, "no aborda exclusivamente problemas relacionados con la enseñanza de las matemáticas escolares. Por lo tanto, la Etnomatemática como campo 
de investigación puede contribuir a valorar y fortalecer el patrimonio sociocultural de los pueblos, comunidades y grupos socioculturales mediante el estudio de sus prácticas" (Peña, Tamayo \& Parra, 2015, p.138).

Este ideal de formación de ciudadanos sólo es posible si se cuenta con docentes que posean una concepción educativa matemática direccionada a la formación de ciudadanos comprometidos, concienciados con la salvación del planeta, que es su única posibilidad de salvación; si la única. Desde luego, esta conformación del ciudadano, de la transgestión de los saberes matemáticos, y por ende el de la enseñanza de la matemática, a la cual se ha venido haciendo referencia se ancla en una renovación profunda de las instituciones educativas. Tenemos derecho a soñar, la utopía es posible. "Tenemos esperanza para el futuro, pues estamos en la época prehistórica del espíritu humano" (Morín, 2000, p.28).

Entre los aportes que el pensamiento complejo debe hacer como condición sin ecua non de la transgestión de los saberes matemáticos esta la transdisciplinariedad en las concepciones constitutivas de dichos saberes. La transdisciplinariedad recorre todo el espectro dentro y a través de las y va más allá de toda disciplina; no margina disciplina alguna, menos la ciencia matemática que interviene en la creación de todos los conocimientos y por ende lleva en su creación la condición transdisciplinar. Su intención es la perspicacia del mundo actual, su premisa y finalidad es la unidad del conocimiento; es desde ese punto de vista que pudiéramos ver el patrimonio cultural matemático como un ente promovido por la enseñanza de la matemática, que se relaciona con todas las disciplinas del saber. No es una mirada la transdisciplinariedad es la vía para poner en práctica la complejizada enseñanza de la matemática.

"La transdisciplinariedad fundamenta sus propósitos de unidad en la complejidad como punto de partida para vislumbrar la realidad". (Rodríguez, 2013, p.41). Es así como la transdisciplinariedad confronta la separación del conocimiento matemático de las demás disciplinas que se desarrollan y solo se investigan dentro de ellas mismas y las construcciones históricas que han establecido los límites de cada una de las disciplinas; pero también confronta la negación de la transversalidad de los saberes matemáticos con el resto de los saberes.

En la utilización de los conocimientos científicos matemáticos como ejercicio de poder en ocasiones se afirma que el advenimiento de transdisciplinar eliminará, por ejemplo, a la disciplina matemática. Esta idea es errada desde la raíz del pensamiento complejo que es integrador y no discriminante. Todo esto puede reconstruirse si vemos que la expresión trans esta imbricada morfológica y semánticamente al concepto de disciplina como la matemática, lo que dilucida, por una parte, la supuesta "eliminación" de la disciplina matemática por la transdisciplinar. 
Se quiere con la transgestión de los saberes matemáticos; en primer lugar, reconocer los saberes soterrados como esencia y valía en igual grado de importancia que los saberes científicos de la propia ciencia; más aún el reconocimiento de que no van separados. Y si se ahonda un poco más en cómo ha devenido la enseñanza de la matemática en los pueblos indígenas en el caso de Venezuela, por ejemplo, se pueden tener expresiones sorprendentes en la historia del conocimiento matemático europeo impuesto a cambio del encubrimiento del nuestro.

También, en segundo lugar, el desarrollo de un currículo adecuado para los pueblos indígenas de en el campo de la enseñanza de la matemática, requiere primero de establecer las relaciones históricas entre la realidad indígena y el desarrollo de la matemática que se desea imponer a estos pueblos ahora culturizados por sus propios hermanos, en la colonización del saber y poder que ha dejado la invasión europea de 1492. La percepción propia de su realidad, sus creencias y costumbres forman patrones de conducta que deben ser estudiados si se desea buscar el modelo de educación adecuado para estos pueblos. Pero que con la Etnomatemática el viraje a dicha enseñanza es muy posible considerando eso sí, lo valioso de cada cultura de los aborígenes. Cuestión imposible de valorizar en la colonización del saber y del poder.

D’ Ambrosio (1990) indica que el origen del pensamiento matemático es una cuestión no resuelta. La búsqueda de explicaciones de por ejemplo las religiones, artes y ciencias, sistemas de valores y estilos de comportamiento en la vida comunal y social, lo psicoemocional, lo imaginario, así como los modelos de producción y propiedad están relacionados con el pensamiento matemático. Existe una creciente producción académica destinada a investigar los distintos estilos y modos de construir el conocimiento en diferentes contextos naturales y culturales donde se reconoce el desarrollo de las ideas matemáticas. Obviamente, en las Américas estos procesos siguieron caminos diferentes a los de Europa, Asia y África.

La invasión y la colonización impuesta de las tierras ahora conocidas como las Américas tuvieron, como una de sus consecuencias, una enorme reorientación del curso de las civilizaciones del continente. Es importante aquí hacer notorio sin duda en cada país y sus grupos étnicos se han desarrollado desde sus inicios manifestaciones culturales que están cargadas de contenidos matemáticos. El patrimonio cultural matemático que aquí se explicita está henchido de un diálogo entre culturas cobrando preminencia por el rescate de la cultura autóctona; aquella olvidada del Abya Yala. Se devela el nombre milenario escondido en la modernidad castradora. En la lengua del pueblo kuna, originario de Sierra Nevada en el norte del país hermano Colombia y que vive en el presente en el Caribe de Panamá, Abya Yala significa tierra madura, viva, en florecimiento, madre o de sangre vital se compone de Abya, que quiere decir sangre y ala, que significa territorio, viene de la tierra y es entonces Abya Yala lo que hoy se denomina América. 
Es Abya Yala la denominación originaria, que luego al denominarlo pueblos indígenas por los invasores y encubridores de nuestro continente les permitió relacionarlos con las Indias, región buscada por los negociantes europeos a finales del siglo XV y de alguna manera justificar la masacre y todo lo ocurrido en el mal llamado descubrimiento de América; tal como lo expresa Rodríguez (2017a).

Desde el Abya Yala, en profunda expresión descolonizada de América, pensando en su patrimonio cultural matemático, también colonizado y gran parte destruido e impuesto después a conveniencia del proceso eterno de apoderamiento de nuestros pueblos y encubrimiento del otro en palabras de Dussel (1993) y otros autores como Quijano (1989). La matemática en la historia del Abya Yala es ocultada y soterrada; por ejemplo, no es notorio haber leído en la historia de la ciencia legado de la humanidad que los Mayas son los inventores del cero, el número más importante.

Los hechos históricos hablan por sí solos, no se puede ocultar que, desde la llegada de los colonizadores europeos, a lo que hoy se conoce como América, los pueblos originarios de estas tierras han sido exterminados paulatinamente, el exterminio se ha llevado a cabo de muchas maneras, entre ellas está el asesinato de los aborígenes, la destrucción de sus casas, templos y ciudades, el saqueo de sus tesoros, el proceso de imposición cultural, religiosa y el esclavismo. Aunado a esta destrucción del acervo histórico-cultural de los aborígenes se observa el menosprecio que han sentido muchos europeos hacia el indoamericano fundamentada en la "inferioridad" del aborigen y una "superioridad" del europeo como ser humano. Estas pretensiones de superioridad donde "primero fue el invasor español, quien pretendió justificar la dominación colonial, en un primer momento por la supuesta superioridad de la religión cristiana católica y, luego, por la supuesta superioridad racional del hombre europeo" (Morales, 1995, p.76).

La matemática y sus grandes descubrimientos fue invisibilizada también con la masacre al continente. La cultura maya, es especial, tantas veces se ha intentado invisibilizar por la colonización, los mayas son grandiosos en las creaciones de la matemática. En simbología son únicos: inventaron un sistema jeroglífico de escritura utilizando imágenes para representar los sonidos, usaban las probabilidades admirablemente contando las palabras utilizando varias combinaciones de alrededor de 800 signos diferentes, asignando a cada signo una sílaba y estas al mismo tiempo se combinaban para crear otra.

Tal sistema legendario de la humanidad inventó tres tipos de calendarios: el Sagrado de 260 días que es el calendario corto dividido en 13 períodos de 20 días cada uno, su utilidad era para los hitos de su agricultura, sus ceremonias religiosas y sus costumbres familiares. El calendario civil o trópico de 365 días que se basa en el recorrido anual de la tierra alrededor del sol en 365 días, para ello dividió el año de 365 
días en 18 períodos de 20 días cada uno y 5 días sobrantes. Y el calendario compuesto por el ciclo de 52 años combinado por 4 períodos de 13 años cada uno.

Los mayas inventaron un sistema de numeración vigesimal, erigieron el número cero, para los que tienen la luz de la creación matemática y la faz de la inteligencia se sabe que el número cero es una esfinge indispensable en las matemáticas. Este concepto de la nada, de lo absoluto carente de característica anulados de los otros es de una maravilla utilidad sin el cual el sistema numérico más usado, el de los números reales no tendría ningún significado. En general "el sistema de escritura del pueblo maya, por su contenido y su ritmo, parece indicar que se trata del producto de una larga tradición oral que fue transmitida y conservada a través de distintos sistemas de escritura como los que componen los Códices" (Ivanoff, 1972, p.356).

Los mayas, con su cultura profundamente compleja creen en lo esotérico, en lo abstracto, en la utilidad y en la vida; por ello representaban el sistema numérico como un sistema de conteo con mínimo tres símbolos para cada uno, para el número cero la representación es un punto, una barra y un símbolo.

En la ilusoria colonización occidentalista de vedar lo nuestro y el pensamiento maya, los ritos eran imprescindibles para garantizar el funcionamiento del universo, el devenir del tiempo, el paso de las estaciones, el crecimiento del maíz, y la vida de los seres humanos. Ésta magnificencia el Continente Europeo estaba lejos de poseer. La astronomía con los calendarios y las probabilidades que predecían fácilmente eclipses solares son de creaciones mayas primerísimas. Esa civilización utilizaba la penicilina para curar a los caciques y tenían sistemas de drenaje pluvial y abastecimiento de agua, ingeniería que no conocían los europeos.

América Latina tiene una historia milenaria, tanto "en su fuente prehispánica como en su vertiente hispano-ibérica; tiene una historia centenaria en su originalidad propiamente latinoamericana -desde el siglo XVI-. Ignorar, olvidar o no tomar conciencia de esa evolución es justamente la característica de una conciencia in-culta" (Dussel, 1973, p.28).

El desconocimiento de nuestra cultura matemática en la actualidad, o su sesgo forma parte de las consecuencias de la colonización de las mentes "si el conocimiento es un instrumento imperial de colonización, una de las tareas urgentes que tenemos por delante es descolonizar el conocimiento" (Quijano, 1989, p.10). Entonces la descolonización del saber de la cultura autóctona, de nuestro patrimonio cultural matemático es de urgencia. Ideas que corrobora Mignolo (2010). Es vivir en el encubrimiento del otro a la que Dussel (1993) titula su gran obra: 1942: el encubrimiento del otro: hacia el origen del mito de la modernidad. En el que de manera magistral intenta explicar que no hubo tal descubrimiento; sino la masacre que pretendió desde la modernidad encubrir el potencial del otro; aquel pisoteado y vejado en su lugar de origen. 
Descolonizar nuestro continente implicará descubrir su historia a partir de los signos y elementos que evocan su caducado patrimonio matemático olvidado no reconocido; transculturizado; muchas veces aculturizado y que ayudan a comprender cómo y por qué ha llegado a ser lo que es; en muchas partes de nuestro continente, el Abya Yala; es aprender de los mayas; son palabras expresadas por Rodríguez y Guerra (2016). A todo esto debe hacer afrenta en la develación de los saberes matemáticos la transgestión.

Se pretende entonces llegar a investigaciones que transciendan los límites de la propia disciplina matemática, y sin excluirla (más bien integrándola) entablando vínculos con otros conocimientos; como el patrimonio cultural matemático, considerándolo como un conocimiento. Es uno de los fines de la transgestión. La finalidad de la transdisciplinariedad "es la comprensión del mundo presente" (Nicolescu, 2002, p.2), en este sentido el patrimonio cultural necesita ser concebido en toda su completitud.

Por otro lado, en la transgestión del conocimiento matemático hay que poner a dialogar los saberes científicos con los saberes soterrados de la matemática; y ello es posible en la ecología de los saberes como reconstrucción de los saberes matemáticos. La autora quiere precisar que como saberes matemáticos incluyen a todo lo referido al asunto de la matemática; sus concepciones, limitaciones, conocimientos, leyes atributos, saberes olvidados soterrados no tomados en cuenta en el filo de la ciencias en palabras de Foucault (1986); toda la complejidad matemática. En principio, la ecología de los saberes es una expresión que viene siendo estudiada por Boaventura Do Santos en muchas de sus obras; por ejemplo Santos (2005) afirma que su propósito es que la universalidad del siglo XXI reconozca la existencia de conocimientos matemáticos plurales, denominada ecología de los saberes; que implica una revolución epistemológica en el seno de la universidad; "consiste en la promoción de diálogos entre el saber científico y humanístico, que la universidad produce, y los saberes legos, populares, tradicionales, urbanos, campesinos provenientes de culturas no occidentales (indígenas, de origen africano, oriental, etc.) que circulan en la sociedad" (Santos, 2005, p.66).

Sin duda, desde la ecología de los saberes, los saberes patrimoniales matemáticos no occidentales auténticos nuestros desde antes de la colonización española entra en conjunción; se pondrían a dialogar con los otros saberes reconocidos en una conjunción donde la complejidad entra en vital funcionalidad no reduccionista de las concepciones de patrimonio cultural matemático, y otros saberes.

En la conjunción de la ecología de los saberes, el conocimiento matemático disciplinar estaría obligado a dialogar con otras formas de conocimiento que fueron dejadas de lado por la modernidad, los saberes patrimoniales matemáticos soterrados olvidados, transculturizados. Es así como, la Educación Matemática Transcompleja cobraría preeminencia y que es tema de estudio de otras indagaciones; pero de la que esta es base. 
Pero, para ello, necesitamos de un pensamiento complejo, de la teoría de la complejidad como base de transformación mental y del accionar humano, capaz de intrincar estos diferentes saberes, así como las diferentes dimensiones de la vida; del ciudadano de su identidad; pero también de su subjetividad. Urge un dialogo transcultural que es "el intercambio no es sólo entre diferentes saberes sino también entre diferentes culturas, entre decir, entre universos de significados diferentes y en un sentido fuerte inconmensurables" (Santos, 2010, p.92).

No hay duda de que sin la complejidad y transdisciplinariedad tal dialogo cultural al que se viene refiriendo no es posible para ecologizar el pensamiento y los saberes matemáticos, con todos los demás y viceversa es preciso la ruptura con la postura obsoleta colonizada. El mismo pensamiento complejo ha permitido que se comience a ecologizar los momentos analíticos y empíricos del enfoque hermenéutico con el propositivo; que se culmina en los siguientes rizomas.

\subsection{Rizoma 2: Pensares transparadigmáticos de la transgestión de los saberes matemáticos}

El tema de la transgestión de los saberes matemáticos como acción humana, en especial en docentes y discentes en la enseñanza de en Venezuela es complejo, enmarcado por características y expectativas personales y laborales que repercuten en actitudes y percepciones ante su quehacer y ante la organización científica, desde las raíces más profundas y la deconstrucción de la gestión tradicional de la matemática. Significa romper con el encierro paradigmático de la formación matemática tradicional de la que muchos aún llevan con orgullo de extinción como científicos.

Pero, ¿cómo hacerlo en la práctica sin la toma de conciencia, sin la reforma del pensamiento al estilo Edgar Morín, sin la reforma de las instituciones educativas?, especialmente porque pocos docentes de matemáticas son conscientes de que están difundiendo una ideología a través de sus enseñanzas, y muchos otros aun sabiéndolo se resisten al cambio, muchos temen perder ese ejercicio de poder como único poseedor del conocimiento matemático; por el contrario, creen que están enseñando a los niños y jóvenes a pensar objetivamente y con rigor científico; cuando la realidad los arropa, en un mundo mediatizado y en plena sociedad de la información; donde con gran ironía y verdad sus discentes manejan con mayor destrezas y prefieren el uso de una computadora como sistema dinámico que interactúa y entre otras realidades pues no castiga el error. Pero no hemos de olvidar, que los sistemas informáticos no abrazan, entre tantas subjetividades del accionar profundamente humano.

Las matemáticas como ciencia, contenida en los saberes matemáticos deben estar a la altura de los problemas que exigen cambios de relevancia cuando educador y educando se unen en una meta y en una idea: El progreso intelectual, moral, espiritual y el cultivo de la conciencia de cuidar el planeta y prepararse para los tiempos venideros, 
pensando que conviven y se educan solo en comunión con el otro, tal como Freire (1997) lo ha hecho notar. La matemática no es la parcela apartada que no interviene en estos asuntos muy por el contrario este asunto ya ha sido de construido en la Educación Matemática Critica y la etnomatemática, para recaer y revocar la ética caducada en la Educación Matemática se requiere entonces un verdadero ejercicio antro poético del ciudadano; que es la antítesis de la ética tradicional, que según Morín (1998) no es más que la ética propia del ser humano, ya que esta abarca un estilo y dinamismo más real y que se adopta más a la verdadera identidad del ser humano en sociedad. Esta nueva definición de antro poética argamasa al individuo, a la sociedad y a la especie, y es el pilar de donde emergen la conciencia y el espíritu propiamente humano. Desde luego, es esencia considerar tal cual Valero (2014) cómo las matemáticas y su educación en la sociedad son parte de los efectos de poder.

En la actualidad, la reflexión de la formación profesional del docente de matemática, en la construcción "de su identidad, se ubica en ésta investigación desde una concepción de la tríada que conlleva a un currículum social, crítico y humanista, que intenta mostrar nuevos espacios educativos que otorguen sentido al proceso de formación profesional desde la matemática" (Rodríguez, 2014, p.107).

La necesidad de que la Educación Matemática en general debe dejarse de ver como un sistema cerrado y que la Educación Universitaria para satisfacer las necesidades de la sociedad debe interrelacionarse permanentemente con los otros sistemas de educación a fin de apoyarse mutuamente en la construcción de los saberes matemáticos profundamente transdisciplinar y complejo que atienda los saberes científicos y soterrados matemáticos en un abrazo y diálogo.

Esto es no paralizarse en la preparación tradicional de sola la disciplina colonizada matemática, que se ha creído cerrada y autosuficiente, obviando los sistemas, las matemáticas fráctalicas; es menester según Morín (2000) luchar contra las cegueras y las ilusiones del conocimiento; examinar las incertidumbres y contradicciones de la realidad; incluir al investigador en su indagaciones; ha caducado desde hace mucho tiempo la total objetividad en las investigaciones, es hora de admitirlo, encararse a la fragmentación del saber matemático; considerar los contextos y visiones de conjunto y no sólo las parcialidades de los mismos.

Todas estas reflexiones también incluyen progresar en el conocimiento transdisciplinar de la matemática a la realidad física, biológica, espiritual y social, generando otras visiones y valoraciones, así como a otras capacidades de respuestas y resolución ante los problemas investigados en el patrimonio cultural matemático. Los medios para formarse están; el docente no tiene excusa para permanecer pasivo ante una realidad que los arropa. 
En el mismo orden de ideas, la perspectiva ecosófica, bioética, y de complejidad de la cultura permea la transgestión de la construcción de los conocimientos matemáticos científicos hacia unos útiles, a las necesidades de la sociedad actual, a los problemas que aquejan en las enfermedades, la hambruna, las guerras, la destrucción del planeta; entre otros.

La matemática como conocimiento y creación humana es cultura como ser esencial del hombre y medida de ascensión humana no sólo concreta la actividad del hombre en sus momentos cualificadores (conocimiento, praxis, valores, comunicación), sino "que da cuenta del proceso mismo en que tiene lugar el devenir del hombre como sistema complejo: la necesidad, los intereses, los objetivos, fines, los medios y condiciones, en tanto mediaciones del proceso y el resultado mismo" (Pupo, 2013, p.1).

Se trata desde estas perspectivas de la visión transdisciplinar e integradora de la cultura, y que debe estar presente en las concepciones de la transgestión educativa. Acá es importante la pertinencia del conocimiento matemático producido, un conocimiento sin aplicación, no es un conocimiento, es importante y valioso si tiene utilidad, "si mejora las condiciones y sirve a la humanidad, muchos trabajos de investigación, con grandes conocimientos, no son conocidos por la comunidad, ni la sociedad civil, y son almacenados en bibliotecas" (Rodríguez, 2012, p.224). El conocimiento matemático es dinámico, capaz de generar razonamiento por ello su importancia radica en ser pertinente, transmitirlo y llevarlo a la praxis. En estos momentos de crisis el conocimiento puede y debe ser la base junto a la acción para ayudar y superar los problemas de la humanidad.

La invitación por una transgestión rica de los saberes matemáticos en Venezuela por ejemplo es de vital importancia, la riqueza del patrimonio cultural matemático desde el patrimonio histórico es digno de investigar en todos los aborígenes en el país. Su importancia ha sido encubierta, por ejemplo en la tribu Warao, pueblo indígena situado en el delta del Orinoco, uno de los ríos más importantes de América Latina y que en su mayor parte transcurre por Venezuela, la antigüedad de ellos en el Delta del Orinoco, Venezuela, es difícil de establecer exactamente, pero los últimos estudios, basados en piezas de cerámica, afirman que sus orígenes se remontan a 17.000 años antes de Cristo. Con estos datos, todo parece indicar que esta tribu es las más antigua del Delta y de Venezuela. El término Warao traducido al castellano significa gente de las canoas. Allí hay una riqueza inconmensurable digna de indagar y recrear en su patrimonio matemático.

\section{Conclusiones y perspectiva futuras}

El rizoma conclusivo, trata de describir la episteme de los saberes matemáticos considerados en la complejidad. De los saberes matemáticos y su asunción, mirada e introspección compleja en la transgestión se develaron consideraciones que se han 
venido dilucidando en los momentos del enfoque hermenéutico y su propuesta de transgestión. Se explicitan a continuación dichas epistemes:

- En los saberes matemáticos, la información transmitida no capta todo el significado de la matemática en la cotidianidad y cultura de los grupos étnicos, sino un experto del momento que jamás de acuerdo con el pensamiento complejo es el mar de incertidumbre desconocido; sino el archipiélago de certeza.

- La relación de los saberes matemáticos entre sujetos es intersubjetiva; se rompe el cerco incluso en las construcciones matemáticas de la objetividad determinada del científico.

- Explorar los saberes matemáticos en los grupos étnicos es sea una tentativa casi intacta para comenzar en las indagaciones de riqueza inconmensurable por crear, para ello una descolonización de ellos y sus consideraciones es urgente; desde luego, basado en la ciudadanía y su identidad, implica ampliar la comprensión de dichos saberes. Bajo la matemática colonizada e impuesta esta tentativa es imposible.

- Los saberes matemáticos patrimoniales entrañan en sí mismo la complejidad, y sólo bajo el pensamiento complejo pueden ser transgestionados y salvaguardados.

- La gestión de los saberes patrimoniales consciente a un docente que atiende a una formación transcompleja de la matemática en consonancias con la triada matemática-cotidianidad y pedagogía integral, de lo que afirma Rodríguez (2013) haciendo trascender el sentido de la Educación Matemática generando en el aula emociones positivas del poder construir matemática de manera armónica sin traumas, pero al mismo tiempo tomando en cuenta la complejidad y así estar comprometidos con la humanidad. Se debe formar así al docente, no sólo para el saber eficaz sino en la inteligencia integral: analítica, sistémica, sensible, corporal y profundamente humana.

- Las epistemes complejas de los saberes matemáticos tienen legitimidad científica para una Educación Matemática Transcompleja (EMT) que es transcendental como debe haber sido la matemática en este lado del mundo, como herencia cultural: nuestro patrimonio cultural matemático. La EMT, es una línea de investigación de la autora, con bastante aceptación internacional; pero que tiene mucho por estudiar en investigar.

\section{Lista de referencias}

Chevallard, Y. (1991). La transposición didáctica. Del saber sabio al saber enseñado. Madrid: Aique Grupo Editor S. A.

D’Ambrosio, U. (1993). Etnomatemática: Um programa em Educação Matemática. Revista $2^{\circ}$ semestre, 1, 5-11. 
Deleuze, G. \& Guattari, F. (1980). Rizoma (Mil Mesetas 1980). Paris: Minuit.

Foucault, M. (1986). "Por qué estudiar el poder: la cuestión del sujeto". En: AA.VV., Materiales de sociología crítica. Madrid: Ediciones La Piqueta.

Freire, P. (1973). La educación como práctica de la libertad. México: Siglo XXI.

Freire, P. (1997). La pedagogía del oprimido. Madrid: Siglo XXI.

Freire, P. (2002). La educación. Autocritica de Paulo Freire a Ivan Illich. Buenos Aires: Galerna.

González, S. (1997). Pensamiento Complejo en torno a Edgar Morín, América Latina y los Procesos Educativos. Santa Fe de Bogotá: Editorial Magisterio.

Gutiérrez, Y. (2017). La transposición didáctica innovadora como base de la enseñanza: una perspectiva desde la etnomatemática, Tesis de Maestría, Universidad de Oriente, Cumaná, República Bolivariana de Venezuela.

Ivanoff, P. (1972). Civilizaciones maya y azteca. Texto de Pierre Ivanoff. Presentación de Miguel Ángel Asturias. Traducción de Juan Blanco Catala. Italia: Arnoldo Mondadori.

Mignolo, W. (2010). Desobediencia Epistémica. Buenos Aires: Ediciones del Signo.

Morales, F. (1995). Etnoinvestigación: El conocimiento científico a la luz de la diversidad cultural. Revista venezolana de Economía y Ciencias Sociales. (Didáctica de las Matemáticas), 1, 75-89.

Morín, E. (1992). El Método IV: Las ideas. Su hábitat, su vida, sus costumbres, su organización. Madrid: Ediciones Cátedra.

Morín, E. (1998). Introducción al pensamiento complejo. Madrid: Gedisa.

Morín, E. (2000). Los Siete Saberes Necesarios a la Educación del Futuro. Caracas: Ediciones IESALC/UNESCO.

Morín, E. (2004). Unir los conocimientos. La Paz: Gedisa.

Morín, E. (2006). El método: La naturaleza de la naturaleza. Madrid: Cátedra Ediciones. 
Nicolescu, B. (2002). Transdisciplinariedad y la complejidad: los niveles de la realidad como fuente de indeterminación. Recuperado de: http://www.basarab.nicolescu.perso. sfr.fr/ciret/bulletin/b15/b15c4.htm

Peña, P., Tamayo, C. y Parra, A. (2015). Una visión Latinoamericana de la Etnomatemática: tensiones y desafíos. Revista Latinoamericana de Investigación en Matemática Educativa, 18(2), 137-150.

Pupo, R. (2013). Ecosofia, cultura, transdiciplinariedad. Revista Big Bag Faustiniano, 2(4), 1-7.

Quijano, A. (1989). Colonialidad del poder, eurocentrismo y América Latina. En libro: La colonialidad del saber: eurocentrismo y ciencias sociales. Perspectivas Latinoamericanas. Edgardo Lander (comp.) CLACSO, Consejo Latinoamericano de Ciencias Sociales, Buenos Aires, Argentina.

Rodríguez, M. (2010a). Pedagogía integral: ruptura con la tradicionalidad del proceso de enseñanza de la matemática. Aletheia. Revista de Desarrollo, Humano, Educativo y Social Contemporáneo, 3(2), 1-16.

Rodríguez, M. (2010b). Matemática, Cotidianidad y Pedagogía Integral: Elementos Epistemológicos en la Relación Ciencia-Vida, en el Clima Cultural del Presente. Tesis de Doctorado, Universidad Nacional Experimental Politécnica de la Fuerza Armada, Caracas, República Bolivariana de Venezuela.

Rodríguez, M. (2011). La ética en la praxis de la tríada: matemática - cotidianidad -y pedagogía integral. Revista educación y desarrollo social, 1, 175-184.

Rodríguez, M. (2012). El papel de la Educación Superior en la producción del conocimiento en el clima cultural del presente. REIFOP Revista Electrónica Interuniversitaria de Formación del Profesorado, 15(4), 119-125.

Rodríguez, M. (2013). La Formación Transcompleja Del Docente De Matemáticas: Consonancias Con La Tríada Matemática-Cotidianidad - Y Pedagogía Integral. Capítulo en el texto Formación Docente: Un Análisis Desde La Práctica. México: Red Durango de Investigadores Educativos, A. C.

Rodríguez, M. (2014). La gestión del conocimiento en las instituciones educativas en el clima cultural del presente. Praxis educativa ReDIE Revista Electrónica de la Red Durango de Investigadores Educativos, 10, 8-27. 
Rodríguez, M. (2017a). La transcomplejidad como transparadigma en las concepciones del patrimonio cultural del Abya Yala. Revista Visión Educativa IUNAES, 11, 108-119.

Rodríguez, M. (2017b). La transgestión educativa transparadigmatica en Venezuela. Praxis Investigativa ReDIE Revista Electrónica de la Red Durango de Investigadores Educativos, 9(17), 118-129.

Rodríguez, M. (2017c). Fundamentos epistemológicos de la relación patrimonio cultural, identidad y ciudadanía: hacia una educación patrimonial transcompleja en la ciudad. Tesis de Doctorado, Universidad Latinoamericana y el Caribe. Caracas, República Bolivariana de Venezuela.

Rodríguez, M. y Guerra, S. (2016). Popol Vuh patrimonio cultural: Serendipiando con sus dinámicas sociales desde la complejidad. Praxis Educativa ReDIE. Revista Electrónica de la Red Durango de Investigadores Educativos, 15, 31-52.

Santos, B. (2003). Crítica de la Razón Indolente Contra el Desperdicio de la Experiencia, Volumen I, Para un Nuevo Sentido Común: La Ciencia, El Derecho y La Política En La Transición Paradigmática. Madrid: Editorial Desclée de Brouwer, S.A.

Santos, B. (2005). La universidad del siglo XXI. México: UNAM.

Santos, B. (2010). Epistemologías del Sur. Utopía y Praxis Latinoamericana, 16 (54), 17-39.

Valero, P. (2014). Political Perspectives in Mathematics Education. In S. Lerman (Ed.), Encyclopedia of Mathematics Education (pp. 484-487). Dordrecht, Netherlands: Springer Netherlands. 